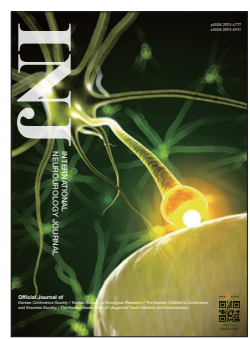

\title{
The Afferent Sensory Pathway: The Unsung Hero of Neural Interactions Controlling Detrusor Contractions
}

\author{
Min Soo Choo (ib) https://orcid.org/0000-0002-7852-5822 \\ Department of Urology, Hallym University Dongtan Sacred Heart Hospital, Hwaseong, Korea \\ E-mail: snuhuro@gmail.com
}

The bladder and lower urinary tract serve to store and evacuate urine and are controlled by a complex interaction of neural mechanisms organized by local, spinal, and brain circuits [1]. During the storage phase, the bladder stores urine and maintains continence via reflexes that prevent contraction of the detrusor smooth muscle and promote contraction of the urethral sphincter. This harmonious coordination is reversed during the voiding phase, when the bladder contracts and the sphincter relaxes to facilitate voiding. This switch relies on signals from afferent sensory nerves, which provide input to the reflex circuits that control bladder filling and emptying.

The sympathetic storage reflex is initiated as the bladder distends, through myelinated $A \delta$-fibers, and the generated afferent activity travels in the pelvic nerves to the spinal cord [2]. Within the spinal cord, sympathetic firing from the lumbar region (L13) is initiated, which, through its effects at the ganglionic level, decreases excitatory parasympathetic inputs to the bladder. Postganglionic neurons release noradrenaline, which facilitates urine storage by stimulating $\beta 3$-adrenoceptors in the detrusor smooth muscle.

Afferent sensory nerve dysfunction leads to a number of disorders, such as overactive bladder and chronic prostatitis/ chronic pelvic pain syndrome (CP/CPPS). Recently, interest in bladder afferent signaling has been driven by the realization that the symptoms of these disorders result from dysregulated storage sensations, rather than exaggerated contractile responses, meaning that targeting afferent mechanisms may be a rational approach to treatment [1]. Furthermore, afferent autonomic sig- naling may induce diffuse reflex mechanisms with a decreased pain threshold in organs distant from the pathologic lesion.

International Neurourology Journal has actively sought out basic research on neural interactions contributing to detrusor contraction, and has published many excellent fundamental research papers in the field of neurourology [3-9]. This issue contains two interesting experimental papers related to afferent sensory nerves.

Park et al. [10] suggest that prostate inflammation activates afferent nerve fibers projecting to the lumbosacral spinal cord, producing reflex activation of spinal neurons innervating the bladder and bladder hyperreflexia. This is mediated by capsaicin-sensitive prostate afferents. Chang et al. [11] propose that in mice, phenylephrine activates the $\alpha-1 \mathrm{~A}$ adrenergic receptor of a sensory nerve, and then activates a capsaicin-sensitive sensory nerve, causing it to release an unknown substance that facilitates the release of norepinephrine from adrenergic nerves. Subsequently, norepinephrine stimulates $\beta$-adrenergic receptors in the detrusor muscle, which leads to neurogenic relaxation of the bladder.

These findings could provide a useful and clinically relevant framework for an approach to treating overactive bladder and $\mathrm{CP} / \mathrm{CPPS}$. If you are interested in neurourology, why not take some time to enjoy these articles during the upcoming summer vacation?

- Conflict of Interest: No potential conflict of interest relevant to this article was reported. 


\section{REFERENCES}

1. Chai TC, Birder LA. Physiology and pharmacology of the bladder and urethra. In: Wein AJ, Kavoussi LR, Partin AW, Peters CA, editors. Campbell-Walsh urology. 11th ed. Philadelphia (PA): Saunders; 2016. p. 1650.

2. Andersson KE. Neurophysiology \& pharmacology of the lower urinary tract. In: Tanagho EA, McAninch JW. Smith's general urology. 17th ed. New York: McGraw-Hill Medical; p. 427.

3. Foditsch EE, Roider K, Patras I, Hutu I, Bauer S, Janetschek G, et al. Structural changes of the urinary bladder after chronic complete spinal cord injury in minipigs. Int Neurourol J 2017;21:12-9.

4. Han JH, Kim SE, Ko IG, Kim J, Kim KH. Afferent pathway-mediated effect of $\alpha 1$ adrenergic antagonist, tamsulosin, on the neurogenic bladder after spinal cord injury. Int Neurourol J 2017;21:17888 .

5. Hattori T, Lluel P, Rouget C, Rekik M, Yoshiyama M. Ketanserin and naftopidil enhance the potentiating effect of alpha-methyl-serotonin on the neurally-induced contraction of human isolated urinary bladder muscle strips. Int Neurourol J 2017;21:20-8.
6. Lee T, Lim US, Kang DH, Jung HD, Kim H, Choi BH, et al. Nearnormalized gene expression profiles in bladder with detrusor overactivity in rats with bladder outlet obstruction after deobstruction. Int Neurourol J 2017;21:247-58.

7. Li X, Liao L, Chen G, Wang Z, Deng H. Effects of acute sacral neuromodulation at different frequencies on bladder overactivity in pigs. Int Neurourol J 2017;21:102-8.

8. Possover M, Andersson KE, Forman A. Neuropelveology: an emerging discipline for the management of chronic pelvic pain. Int Neurourol J 2017;21:243-6.

9. Salazar BH, Hoffman KA, Zhang C, Kavanagh A, Zhang Y, Boone $\mathrm{TB}$, et al. Electrical activity of the bladder is attenuated by Intravesical Inhibition of $\mathrm{P} 2 \mathrm{X} 2 / 3$ receptors during micturition in female rats. Int Neurourol J 2017;21:259-69.

10. Park JS, Jin MH, Hong CH. Neurologic mechanisms underlying voiding dysfunction due to prostatitis in a rat model of nonbacterial prostatic inflammation. Int Neurourol J 2018;22:90-8.

11. Chang HH, Chang SJ, Hsieh CH, Hsu CK, Yang SS. Capsaicin-sensitive sensory nerves indirectly modulate motor function of the urinary bladder. Int Neurourol J 2018;22:83-9. 